\title{
LA IMPLANTACIÓN DE LAS TECNOLOGÍAS DE LA INFORMACIÓN EN LA SOCIEDAD Y EN LOS CENTROS EDUCATIVOS PÚBLICOS DE LA COMUNIDAD DE ANDALUCÍA
}

\section{Javier Barquín Ruiz $\left(^{*}\right)$}

SÍNTESIS: EI presente trabajo recoge las principales líneas y modalidades de introducción de las TIC en los centros educativos de primaria y de secundaria de la Comunidad Autónoma de Andalucía. El proyecto andaluz apuesta por el uso del software de código abierto (Linux), por distintos apoyos al desarrollo del mundo rural, y por ayudas a las familias para que accedan a contenidos digitales. La filosofía del proyecto intenta compensar la desigualdad digital en el medio social y escolar a través de una estrategia global.

Una de las retóricas que recorre hoy la mayoría de los Estados y de sus respectivas administraciones es la presencia y la polivalencia de los recursos digitales como garantes del desarrollo económico y como necesidad social y cultural. Una sociedad moderna, la del siglo XXI, exige una presencia constante de los medios digitales en todos los ámbitos que precisen dar respuestas a las demandas del mercado. La dependencia en este sentido es abrumadora. Baste pensar qué sucedería si los ciudadanos de España (uno de los países con mayor presencia de cajeros automáticos) no pudieran utilizar sus respectivas tarjetas de crédito. Lo mismo se puede decir de un apagón de las antenas que conectan los móviles (celulares) 0 de la red que difunde los contenidos televisivos. ¿Podemos imaginar una sociedad que careciera tan solo de los elementos citados? Vivimos en red, consumiendo en todo momento contenidos digitales de muy distinto signo, y en una sociedad cuyos grupos sociales tienen diferentes posibilidades para disfrutar y/o acceder a la oferta de la sociedad digital. Para entrar de pleno en la «sociedad informacional» (Castells), se necesitan tanto recursos materiales (capacidad económica) como una cualificación en los medios (saber manejar la tecnología). Lo que sigue tratará de mostrar cuáles son las medidas arbitradas por la Administración Pública de Andalucía para fomentar el acceso a la sociedad del conocimiento y para solventar la brecha digital en distintos planos de actuación ciudadana y escolar.

(*) Departamento de Didáctica y Organización Escolar, Facultad de Ciencias de la Educación, Universidad de Málaga, España. 
1. MEDIDAS DE IMPULSO DIGITAL

Para hablar de las resoluciones decididas por los poderes públicos, tenemos que referirnos al Decreto 72/2003, de 18 de marzo, sobre Medidas de Impulso de la Sociedad del Conocimiento ( BOJ A, n. 055 , de 21 de marzo de 2003). Este documento no se ciñe sólo al ámbito educativo, sino que se traslada a un marco general muy ambicioso en el cual se contemplan varios apartados. Muy sucintamente, el Decreto contempla una serie de capítulos y de espacios de actuación que reseñamos a continuación: 


\section{Decreto 72/2003 \\ Sociedad del conocimiento}

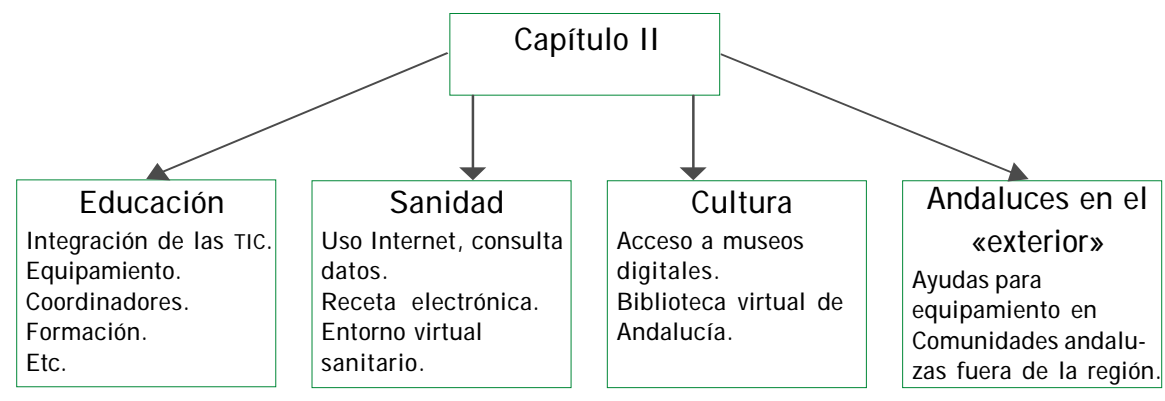

\section{Capítulo III}

\section{Acciones para la alfabetización digital}

Para adultos formación en centros educativos, en centros Día, centros municipales, bibliotecas, etc. Se proporciona correo electrónico gratuito, sotfware libre, etc.

\section{Capítulo IV}

Investigación, desarrollo e Innovación

Ayudas para la formación de doctores, perfeccionamiento, inserción laboral, fomento de la investigación, etc.

\section{Capítulo V}

Ayudas a las empresas andaluzas

Fomento incorporación de las tecnologías, ayudas a autónomos y mediana empresa, apoyo al sector tecnología y audiovisual, etc.

\section{Capítulo VI}

Reutilización de equipos y otros residuos electrónicos Creación de infraestructuras, puntos limpios, educación ambiental, etc. 
- El apoyo digital se traduce en cuatro portales, que con diferente estructura y funciones pretende colaborar en la formación y en la difusión digital.

- El portal www.andaluciajunta.es es el que recoge noticias y el lugar donde se accede al correo electrónico vía web. Constituye el lugar principal dentro del proyecto y tiene marcado carácter institucional.

- El portal www.guadalinfo.net está dedicado a los centros digitales rurales. Trata de dar apoyo a ciudadanos y a empresas ${ }^{1}$.

- Un tercer apoyo lo tenemos en www. guadalinex.org, donde se difunden las bondades del código abierto mediante la creación de un CD-LIVE, de foros, de consultas en el uso del denominado Guadalinex 2004, que es la última versión estable. Se pueden obtener imágenes del CD y otras ayudas para instalación, etcétera².

- Y, por último, la versión educativa, que encontramos en and@red dentro del portal especifico de la Consejería de Educación (www.averroes.juntaandalucia.es). Este espacio sirve de contacto y de difusión de la evolución del proyecto, que empezó en el curso 2003/2004. En la actualidad son 300 los centros TIC y/o DIG que componen el total en su segundo año de experiencia. En and@red encontramos información sobre el proyecto, sobre enlaces, sobre noticias, sobre la relación de centros y sus páginas web, etcétera.

\footnotetext{
${ }^{1}$ Las previsiones para el año 2006 contemplan la instalación en 636 municipios de centros de acceso digital públicos. Así cubrirían a una población total estimada de 1.700 .000 personas que viven en localidades menores de 10.000 habitantes. En la actualidad existen 142 centros abiertos. Los últimos datos de la Asociación para la Investigación de Medios de Comunicación (AIMC) (abril-mayo 2004) indican que sólo el $1,6 \%$ de las clases de rentas bajas accede a la red. El programa Red.es, de ámbito nacional, pretende reducir esa brecha en el uso de la red motivado por causas socioeconómicas.

${ }^{2}$ El acuerdo con la Administración de Extremadura ha servido para desarrollar un software que combina el sistema operativo y determinadas aplicaciones básicas (procesador de textos, navegador, correo electrónico, etc.). EI CDse puede obtener a través dela red y se reparte gratuitamente. Por ejemplo, en el pasadosıM02004 (exposición anual que se realiza para presentar lasúltimas novedades en la materia) se distribuyeron 20.000 copias y se realizaron más de 3.000 descargas en los primeros días de su aparición en el portal.
} 
La estructuración y el reparto de áreas da lugar a la presencia de espacios complementarios, en cuanto que atienden ámbitos específicos tanto en el entorno educativo y el tejido económico (sobre todo pequeñas y medianas empresas), como en los aspectos social y ciudadano.

Para hacernos una idea de las pretensiones de la Consejería de Educación aportaremos algunos datos, recogiendo ciertas proyecciones y el grado de implantación actual.

La Comunidad andaluza presenta una matrícula en los centros públicos (datos del curso 2003/04) de 1.075 .462 alumnos, en la que se incluyen desde el preescolar hasta los programas de Garantía Social. De ellos, más de 700.000 pertenecen a los ciclos de primaria y de secundaria, que es donde se concentra el proyecto And@red.

Los datos más significativos sobre organización del sistema educativo público serían los siguientes:

- Centros de primaria: 1.948

- Centros de secundaria: 1.334

- Número de docentes (todos los niveles excepto universidad): 83.754

- Número de unidades 1ạ: 19.147

- Número de unidades ESO: 11.699

- Ratio primaria: 20,7

- Ratio ESO: 26,1

Las previsiones numéricas estiman un conjunto de varios miles de ordenadores (computadores) en un futuro cercano, ya que todas las escuelas de Andalucía contarán con banda ancha y con una media de un ordenador por cada dos alumnos, aparte de otros materiales como impresoras, proyectores, etc. Si observamos los números en cuanto a unidades escolares y a alumnado, podemos comprobar con una simple operación de multiplicar que las cifras del posible conjunto de ordenadores se disparan a centenares de miles. 
También se modifica el mobiliario escolar, las dotaciones para seguridad en los centros, la presencia de empresas de atención técnica, etcétera.

Pongamos un ejemplo: la adaptación técnica de un centro de secundaria ha supuesto la instalación de cerca de 47 kilómetros de cable y la remodelación total de puntos de luz, de potencia eléctrica, etc. Algunos expertos en la red sostienen que la inversión en ordenadores, por sí sola, no es un factor de éxito. El problema consiste en modificar los procesos de producción y de organización ${ }^{3}$. En este caso, los análisis sobre la empresa son fácilmente trasladables al mundo educativo. ¿Qué impacto tiene en la organización escolar y en el uso/construcción del conocimiento la presencia del ordenador? En parte dependerá de la manera en la que el grupo responsable hace operativo y optimiza su potencialidad en un espacio tan abierto como es el de la enseñanza, donde coexisten fórmulas tradicionales de ejercer la docencia como experiencias innovadoras que muestran su cara más débil a la hora de conocer el impacto real frente al aprendizaje. Aunque este apartado puede extrapolarse al conjunto de la educación, ciertas pruebas internaciorales (v. gr. los informes PISA) recogen limitados aspectos de los efectos de la enseñanza.

Como vemos, el esfuerzo inversor es considerable, ynunca antes una administración había dedicado semejante desembolso ${ }^{4}$ para un proyecto de innovación, aunque en este caso el acento del costo recaiga sobre lo material y no tanto en la formación, puesto que tal responsabilidad corresponde de forma genérica a IOS CEP, cuya infraestructura también ha sido remodelada en parte para disponer de unos medios similares a los que utilizan los docentes en sus centros.

Los expertos recomiendan destinar un $30 \%$ del presupuesto del proyecto a formación del profesorado, que es uno de los pilares más importantes. En el caso andaluz, es difícil estimar qué porcentaje del total se está destinando a la formación.

Algunos estudios señalan que sólo una tercera parte del profesorado se siente algo preparado para introducir el uso de las TIC en su

\footnotetext{
${ }^{3}$ PISA, f. EI País, 22/VII/2004.

${ }^{4}$ En los dos últimos cursos se han destinado más de 100 millones de euros a desarrollar el proyecto. En el apartado de ordenadores se han enviado más de 37.000 a los centros TIC y DIG. Alrededor de 100.000 alumnos/as se benefician de estas medidas.
} 
trabajo. En este sentido la U nión Europea coincide, y así lo ha expresado en diversos informes (Learning in the Information Society. Actions plan for a European Education Initiative (1996-98); en eEurope; en Una Sociedad de la Información para todos (Comisión Europea, 2000c); en Key Data on Information and Communication Technology in Schools in Europe (2004); este último describe una serie de indicadores sobre el estado de las TIC en los sistemas educativos europeos ${ }^{5}$.

El apartadom ásllam ativohasidblaeleccióndel software libre o de código abierto, merced a un acuerdo con una distribuidora del ámbito del Linux y otro con la J unta de Extremadura, que había iniciado años antes el uso del software libre en la administración.

Lograr una versión estable para el ciudadano ha significado un trabajo de varios meses, mientras que para la versión educativa el caso ha sido distinto, puesto que su desarrollo ha estado marcado por la plataforma educativa y por el control y el mantenimiento de los ordenadores a través de un servicio específico, el CGA (Centro de Gestión Avanzado de Centros TIC y Digitales), que se encarga del mantenimiento de la plataforma, de la actualización del sistema operativo, de los programas, etcétera.

EI CGA administra los servidores y las redes locales de Centros TIC, DIG y el Centro de Atención de Usuarios. Da soporte de conectividad al resto de los centros educativos públicos de niveles no universitarios de Andalucía. También administra el mantenimiento de paquetería del Sistema Operativo de fuentes abiertas, Guadalinex, instalado en los equipos informáticos de los centros educativos. El CGA descarga del aspecto tecnológico a los profesores, y sólo les deja el pedagógico. La idea es liberar a los profesores de la servidumbre que sería saber también informática.

La puesta en marcha del proyecto se realizó a través de un concurso abierto, con una serie de condiciones para los centros, y del equipo de trabajo que de manera voluntaria quiso participar. El primer año fueron 50 centros TIC y otros 50 denominados Centros Docentes Digitales, DIG, del total de 626 solicitudes recibidas.

\footnotetext{
${ }^{5}$ Según el informe de 2004, en la enseñanza pública había un ordenador por cada 21 alumnos en el tramo de edad de 15 años.
} 
En el curso $2004 / 05$ son ya 150 centros TIC y otros tantos DIG los que han recibido la aprobación correspondiente. En algunos casos, ciertos centros participan de las dos condiciones: TIC y DIG.

La Administración ha definido así su visión de un centro TIC: «los centros de Tecnología de la Información y la Comunicación, TIC, son institutos o colegios que incorporan las TIC como herramienta educativa en la enseñanza-aprendizaje. La filosofía que se aplica en estos centros no va encaminada a 'aprender informática', sino a usar la 'informática para aprender'. En estos centros la interacción va dirigida al personal interno del centro como a profesores y alumnos, y se pretende que el ordenador no sustituya la programación educativa sino que sea un instrumento que complemente la formación de los alumnos. Estos centros disponen de equipamientos informáticos e Intranet; de plataforma educativa -And@red-con contenidos y recursos educativos; y de soporte y servicios técnicos».

Como apoyo al proyecto, la Administración dispuso que en cada centro existiera un dinamizador, sin perfil informático, que orientara sobre recursos educativos, que asesorara en la solución de problemas, etc. En la práctica, cada coordinador ha desarrollado su cargo bajo muy variadas condiciones y actividades.

Los centros docentes digitales, DIG, son institutos o colegios que usan las TIC para facilitar las gestiones administrativas y académicas entre el centro, el profesorado, el alumnado y las familias. A diferencia de los Centros TIC, que están orientados al personal interno, los Centros DIG se dirigen al externo del colegio. Estos centros disponen de equipamiento informático, de Intranet, de plataforma de contenidos PASEN-, de soporte y de servicio técnico. La plataformaPASEN es un portal de contenidos que facilita la comunicación entre los padres y tutores y los profesores del centro. Novedosa en su concepto, parece que no es muy utilizada.

El curso 2003/04 se caracterizó por el inicio del proyecto en centros que estrenaban plataforma, pupitres dobles con un ordenador encastrado, aulas renovadas y con el material fijado al suelo, etc. Pero, sobre todo, significaba un reto para todos los claustros que habían aprobado pertenecer y desarrollar un proyecto determinado, basado en el uso de ordenadores con un software novedoso. Los profesores/as se enfrentaban a una estructura de aula en la cual los monitores formaban una especie de tercer elemento entre dos cabezas de alumnos, que, según 
el momento, atendían más a la pantalla, se repartían el teclado y hacían distintas operaciones más o menos activas o participativas.

El profesor tenía que reestructurar sus modos de manejar tanto la información como las tareas de sus alumnos. Ahora disponía de un proyector para fijar la atención de toda la clase hacia determinada información, y también de una pantalla para cada dos alumnos. A partir de ahí podía mostrar datos de elaboración propia, como acceder a la red con determinadas limitaciones ${ }^{6}$.

El alumnado no ha tenido especiales dificultades en usar la plataforma Guadalinex y en moverse con el ratón por los programas y por la red. La visión de alguna experiencia que va conociéndose no muestra un panorama muy problemático, sino que más bien es un nido de expectativas entre los profesores que son usuarios avanzados y los neófitos. Parece que la organización y el no imponer el uso de los ordenadores facilitan la convivencia de diversos estilos de enseñanza y de uso de los medios en los centros ${ }^{7}$.

Más problemas han existido en el campo del profesorado, tanto en el que voluntariamente había aceptado participar como en el de los colegas que observaban desde fuera la experiencia. La premura en instalar la versión educativa de Guadal inex significó que al gunos programas y el manejo del sistema operativo mostraran fallos y dificultades. Eso supuso muchas críticas y la defensa de sistemas propietarios y de programas ligados ${ }^{8}$.

De todos modos, no se entró en una guerra sobre las bondades y las limitaciones de Guadalinex frente al resto, pero no por ello en los centros se dejó de usar lo instalado previamente. Los usuarios comprendieron que no llevaba a ninguna parte tratar de imponer una opción.

\footnotetext{
${ }^{6} \mathrm{P}$ ara evitar el acceso a páginas no recomendables desde el centro de control, seleccionaron determinados térmicos de filtro. Sólo que el filtrado, al tiempo que evitaba el acceso a paginas pornográficas, por ejemplo, también limitaba el acceso a portales educativos. En este sentido, la limitación carece del refinado técnico necesario para distinguir lo correcto de lo incorrecto.

${ }^{7}$ Puede verse en Feria (2004) una descripción del funcionamiento de un centro extremeño que usa Linux.

${ }^{8}$ Es conocido el dominio de microsoft y sus diferentes versiones de windows en el panorama del ordenador doméstico, pero también en algunos centros minoritarios que utilizan macintosh el rechazo a la plataforma Guadalinex era el mismo.
} 
De esa manera se reconocían las limitaciones de la nueva plataforma, puesto que su uso significaba aprender nuevos métodos de manejar el sistema frente a lo ya conocido, que parecía más asequible y cercano al usuario.

Pero, ideológicamente, el discurso del código abierto, asociado a un movimiento cooperativo y libre como el Linux, era un argumento poderoso y muy adecuado para el trabajo en administraciones públicas.

Aunque el apartado pedagógico no debiera estar contaminado por la parte técnica, muchos docentes ${ }^{9}$ apostaron por el proyecto al estar basado en el movimiento de código abierto. Para Quéau (2002) un bien público está constituido por los protocolos de Internet y por el acceso a la red, aunque considera que son infrautilizados por un determinado grupo de la población mundial, no sólo por su poca accesibilidad sino por el analfabetismo digital. La propuesta de utilización del software libre conecta con su propuesta de principios para la defensa de los bienes públicos mundiales:

- El principio de inalienabilidad. Los bienes públicos son inalienables; por tanto, no es posible privatizarlos.

- El principio de interés mundial o principio de subsidiariedad. El ejercicio de la soberanía sobre los bienes públicos mundiales revierte en la comunidad global, que se compone de individuos, no de Estados (enunciado del principio del jus gentium). Cualquier persona, por el hecho de haber nacido, es copropietaria del inmenso dominio público mundial. He aquí un nuevo derecho del hombre pendiente de un reconocimiento explícito. En consecuencia, cualquier persona está legitimada para participar en la administración de los bienes públicos mundiales.

La «justicia social mundial» es el bien público por antonomasia (p. 200). La filosofía del Decreto 72/2003 está contagiada de estos aspectos, que se extienden poco a poco por el Estado ${ }^{10}$.

\footnotetext{
${ }^{9}$ Este grupo de docentes, a su vez, era minoría dentro de los centros educativos.

${ }^{10}$ Tanto en Comunidades Autónomas como en universidades se están realizando CDS con sistema Linux y paquetes de aplicaciones que se distribuyen gratuitamente. Entre otras, podemos citar las Comunidades Autónomas de Extremadura y Castilla-La Mancha, así como las Universidades Oberta de Cataluña, de Valencia, etc. Las actuaciones en esta materia se multiplican dentro de las administraciones públicas.
} 
A continuación planteamos algunas interrogantes que pueden cuestionar el proyecto, y, al mismo tiempo, iluminar aspectos controvertidos.

\section{1 ¿DE QUÉ MANERA HA MEDIADO EL SOFTWARE EN LOS RESULTADOS O EN LA EVOLUCIÓN DEL PROYECTO?}

Esta cuestión fundamental requiere contemplar la historia de los centros y de los profesores/as respecto al uso de los medios desde la aparición de los primeros ordenadores en los centros. En primer lugar, los docentes voluntarios no eran novatos frente al uso del ordenador, y bien a través de la realización de páginas web, del manejo de programas de aplicación, etc., bien mediante cursos realizados en los últimos años, podían tipificarse como usuarios avanzados. Eso facilitaba un conocimiento base para enfrentarse a un sistema con características propias, que obligaba a utilizar comandos y no tanto al uso del ratón para determinadas acciones.

Las bases de la convocatoria suponían una cierta trayectoria en el uso de las TIC, con lo cual se buscaba iniciar la experimentación contando con centros y con grupos de docentes más o menos expertos. Con el paso del tiempo y ampliando los centros experimentales, se podían ir conociendo los problemas de implantación y reconducir en todo caso el plan inicial.

En el último año se han producido ceses y dimisiones entre los responsables de la política educativa, y eso también puede propiciar cambios en los modelos de implantación. De hecho, las últimas reuniones patrocinadas por la administración, en las cuales han participado docentes, directivos y personal de formación, han significado una puesta en común, donde ciertas contradicciones y problemas (así como las soluciones particulares de algunos centros y de ciertos docentes) se han trasladado a los responsables políticos. Queda por ver qué tipo de decisiones se van a producir en un futuro cercano, y hasta qué punto las diferentes orientaciones y visiones de ambas partes pueden acercarse para materializar acciones e ideas en la práctica. 


\section{2 ¿QUÉ SE HACE EN LOS CENTROS TIC?}

El proceso de enseñanza se ha modificado, al menos espacialmente, por la configuración tipo autobús de las aulas (pupitres alineados en filas). Parte del profesorado de primaria no se encuentra cómodo con esta fórmula, y en ciertos centros se ha retocado en lo posible la composición, además de manifestar su preferencia por aulas en las que se pueda realizar otro tipo de agrupamientos y de actividades. En secundaria parece que el debate sobre este punto es menor, centrándose en la falta de contacto visual con los alumnos, tapados por el monitor, que, por otro lado, ha aumentado de tamaño en las últimas entregas.

Más difícil resulta describir la posible innovación resultante en materiales y/o en estrategias de enseñanza. Para algunos, lo que se ha logrado es hacer libros animados y poco más (lo cual tampoco resulta novedoso). La red se utiliza para buscar información, pero de manera estanca. Se obtiene la información sin relacionarla con modos de investigación o para integrarla en proyectos de trabajo. En efecto, la red es una gran enciclopedia, pero se vuelve a la crítica anterior: en lugar de utilizar la enciclopedia de la biblioteca, se obtiene información a través de la red. No es, por tanto, problema de información, sino de su utilización (por qué, para qué, cómo, etc.) de esta información.

Tal vez nos encontremos en una fase rudimentaria y preliminar en el descubrimiento del verdadero potencial de la red, de sus recursos, o, simplemente, lo analógico se hace ahora de forma digital, sin que ello suponga un avance significativo y distinto en las fórmulas de conocimiento y de desarrollo cognitivo. Anteriores estudios en el uso del ordenador señalan que, desde el dominio de la herramienta hasta el cambio real en los procesos de enseñanza, suelen transcurrir algunos años.

\section{3 ¿SE HAN CAMBIADO LAS LABORES Y LAS TAREAS DEL DOCENTE?}

En la clase tradicional el docente estructura y dirige los quehaceres, supervisando el flujo de información y controlando los tiempos de las tareas, el tipo de las mismas, etc. Ya sea mediante exposiciones magistrales (donde la información descansa en el docente), ya por la actividad que se realiza (siguiendo las directrices y el control del profesor), el cambio hacia fórmulas más innovadoras no implica hacer las mismas cosas a través de una pantalla o utilizando Internet. Si el alumno utiliza el ordenador para realizar las tareas que antes escribía sobre un 
cuaderno, no estamos en realidad ante un cambio del modelo propiciado con la ayuda de las TIC.

\section{4 ¿SE HAN PRODUCIDO ALTERNATIVAS AL MANEJO DE LA INFORMACIÓN Y A LA CREACIÓN DE CONOCIMIENTO?}

Para algunos docentes la creación de páginas web, de documentos de imagen y de texto, etc., por parte de sus alumnos constituye un avance, y, como tal, podemos encontrar páginas web de centros donde se exponen los trabajos de los estudiantes. En ese sentido opinan que una educación para la sociedad digital pasa por el mayor uso posible de las herramientas TIC, yentienden como un avance en el aprendizaje el hecho de que el niño/a sea capaz de expresarse utilizando herramientas multimedia y textos mixtos. Junto a esto existe la idea del elemento compensatorio, que supone para ciertas familias que sus hijos puedan utilizar ordenadores en el centro, puesto que carecen de él en el hogar ${ }^{11}$.

Pero, al mismo tiempo, se oyen voces que dudan sobre el avance real en materia de innovación y de cambio en las prácticas de enseñanza. En la actualidad están en fase de preparación una serie de estudios que pretenden conocer el impacto de este proyecto en la docencia, aunque algunas manifestaciones pueden observarse en las páginas web de los centros y en el portal específico del proyecto.

Una ausencia significativa es la universidad, como estamento educativo y de investigación aplicada. No se entiende que, con la existencia de parques tecnológicos y de facultades y escuelas técnicas repartidas por toda la geografía andaluza, no exista algún programa específico de apoyo al uso de sistemas no propietarios y al desarrollo de los mismos para el marco educativo. El capital que proporcionan tanto docentes como alumnos de cara a su implicación en posibles proyectos relacionados con centros educativos y/o con grupos de docentes donde

\footnotetext{
${ }^{11}$ Por otro lado, el informe de Eurydice (2004) sobre el uso de las TIC en los centros educativos de Europa indica una gran variedad entre Estados, yun uso más acusado en los niveles superiores y mucho más bajo en los primeros años de escolarización; además, se carece de datos de los niveles de infantil o de primaria. Por ello parece que, gl obalmente, el esfuerzo por dotar de alguna presencia a las TIC en los centros, al menos proporciona algún tipo de contacto o de conocimiento de estos medios para capas de población que no poseen este recurso. En la lógica que parece presidir los indicadores que manejan los países desarrollados, es necesario aumentar nuestro Índice de uso digital partiendo de los primeros niveles escolares (Barquín, 2004).
} 
pudieran proporcionar apoyo técnico, se lograría con un desembolso económico irrisorio en proporción con el previsto para el proyecto total a medio plazo. Al mismo tiempo, se irían capacitando futuros profesionales procedentes de las facultades de informática y similares en herramientas que la propia administración está proporcionando a las pequeñas empresas.

Si se trata de diseminar en todo el sistema social y económico otra concepción de las posibilidades de la sociedad de la información y del código abierto, las estrategias deben dirigirse a todas las agencias, que, a corto y medio plazo, proporcionan un capital humano susceptible de usar y de potenciar estas herramientas de comunicación social y de desarrollo económico.

\section{OTROS EFECTOS}

Uno de los postulados más críticos de la academia con el mundo docente es la presencia en los centros de un individualismo y de una defensa espuria de la libertad de cátedra, que, a veces, esconde el miedo a contrastar sus ideas y sus prácticas, junto a la duda de la bondad de su diseño del proceso de aprendizaje. En tal sentido, se ha logrado una filosofía que invita a compartir los productos y las ideas que surgen en la práctica. Uno de los objetivos que manifestaba un jefe de estudios era, por ejemplo, la necesidad de un espacio donde al ojar las experiencias que se iban produciendo en su centro, y que estuvieran abiertas a cualquier usuario de la red.

Parece probable que este sentido de comunidad no se ha producido sin más por usar el ordenador o por participar en el proyecto And@red, pero está de acuerdo con una filosofía que recorre la comunidad Linux y que también proporciona la flexibilidad de los medios digitales.

El profesorado del proyecto quiere compartir ideas, programas, productos de sus alumnos, etc., y la plataforma creada anima y facilita esta posibilidad. En un reciente estudio sobre el uso de Internet (Gargallo, en prensa) se recogen una serie de recomendaciones que existen en el proyecto And@red, como son la figura del coordinador, la existencia de un equipo técnico de apoyo, la creación de una base de datos de experiencias, etc. En ese sentido, parte de las propuestas está 
en consonancia con la experiencia y con los datos que aporta la investigación.

\section{LAS RESISTENCIAS DEL PROFESORADO}

La realidad de los centros nos muestra cómo la diversidad de intereses y de actitudes presentes en los claustros da lugar a muy diferentes grados de implicación en la innovación. Determinados centros son conocidos por su casi permanente presencia en proyectos, y el cambio parece ser una constante a lo largo de los cursos. Este tipo de centros constituye una minoría dentro del panorama general, que parece lastrado por un pesimismo o por una desidia, en parte tópico y en parte realidad.

En Andalucía han sido centenares los centros que han solicitado su adscripción al proyecto And@red. Ahora bien, merece la pena detenerse a pensar en aquellos que no se distinguen por su trayectoria innovadora, y aventurar hipótesis que expliquen el rechazo hacia las TIC.

Creemos poder señalar algunas razones. Una de ellas tiene que ver con la incongruencia de las necesidades y de los recursos. Muchos centros solicitan al mismo tiempo mejoras en sus espacios como profesores de apoyo, 0 , simplemente, alguien que cubra las bajas. Mientras comprueban que tales necesidades básicas no se cubren, pueden ver cómo miles de ordenadores ( $y$, por consiguiente, millones de euros) llegan a los centros, y se preguntan si antes no debieran ser tenidas en cuenta otras prioridades del sistema.

Los docentes se plantean si no es suficiente con tres o cuatro ordenadores en el aula y alguna sala de informática. La mayoría de los centros no se opondría a tales medidas.

Sin embargo, se publicitan otros modelos y otras situaciones en los que centenares de ordenadores inundan aulas y centros. Este tipo de introducción de las TIC no gusta a un amplio sector del profesorado. Una mezcladetem orycentim ientode descualificación concita el rechazo a esas aulas, donde los ordenadores predominan sobre la labor o sobre la figura del docente. 
La mayoría del profesorado está acostumbrada al uso del libro y del cuaderno de trabajo. Enfrentarse a una clase en la cual el ordenador es el mediador del aprendizaje exige una revolucionaria reconversión de los docentes y de las estrategias de enseñanza. Esto, claro está, si el ordenador estuviera siempre en uso durante todas las horas de docencia. Como tal situación no parece que pueda esperarse (ni creemos que sea recomendable), el sentido común debiera prevalecer entre todos, de modo que la administración admitiera un cambio en el modelo, y el profesorado empezara a contemplar seriamente que la red Internet y el ordenador pueden ayudarle en los procesos de enseñanza.

Así, una parte puede redistribuir ordenadores (que no sean centenares para cada centro) y recursos, y la otra continuar sus procesos de cualificación técnica y pedagógica en el uso de las TIC. A ello puede ayudar la presencia en menor escala en las aulas de ordenadores y la labor de las agencias de formación permanente, que deben estudiar un plan a medio plazo para todo el profesorado.

\section{OTRAS CONSIDERACIONES}

Sin tener suficientes datos sobre el desarrollo de la experiencia, cabe reflexionar sobre los procesos de enseñanza-aprendizaje que pueden provocar unos medios distintos a los habituales, en los que su presencia, manejo y desempeño requieren determinadas habilidades yla reestructuración de espacios y de tareas.

¿Qué cambia el uso del formato digital y la pantalla en una clase con pupitres fijos? Sin duda, tanto la plasmación de las actividades del alumno/a como su reflejo requieren otro tipo de regulación. En las aulas normalizadas el uso del libro de texto (o de consulta), junto con el cuaderno de tareas o de apuntes, constituyen elementos de datos, ya para leer o para escribir). El libro, con su contenido texto-icónico, es fácilmente accesible y manejable, admite un trato poco amigable y no necesita energía para utilizarse. A su vez, el cuaderno es un recipiente con cierta semejanza, personalizado por las características propias de su dueño, que tampoco exige para su mantenimiento especiales recursos, a no ser la constancia y la dedicación para tenerlo al día.

Frente a estos dos elementos de la «galaxia Gutemberg» aparece un ordenador, que, con sus programas de aplicación y con su pantalla, 
puede suplantar parte de lo que proporcionan tanto el libro como el cuaderno. Por medio del ordenador se obtienen cantidades ingentes de información, y en su disco duro pueden almacenarse miles de páginas y de trabajos de los alumnos/as. Al mismo tiempo, determinados programas de diseño, de animación, etc., pueden lograr entretenidas presentaciones gracias a la combinación de imagen animada, de texto, etc. Los apuntes, los dibujos de muchos cuadernos de los estudiantes palidecen ante las posibilidades técnicas del ordenador. Gracias al computador, cualquier alumno puede ocultar su mala caligrafía o su incapacidad para el dibujo a través de lo que está en posibilidad de obtener de la red o de determinados programas. Los diseñadores ponen a disposición del público sus productos para que el usuario combine yjuegue con multitud de probabilidades. Así, la factura de muchos trabajos escolares puede carecer de imaginación, pero despliega un gran aparato de música, de imágenes en movimiento, de efectos especiales... que son básicamente un envoltorio que distrae del problema del contenido. Pero muchos profesores y estudiantes consideran estos trabajos como una manifestación exitosa de la presencia de las tecnologías en la escuela.

Sin negar el posible avance para el ocio o para la estética digital que supone el dominio de programas, queda por dilucidar su impacto para áreas básicas del currículo tanto en el lado del contenido troncal como en el más difuso de los valores.

La denominada sociedad digital, informacional, red, globalizada y un largo etcétera de epítetos, también debe admitir la crítica a sus planteamientos y a sus efectos en la sociedad (se habla de inforicos y de infopobres), de su cuestionable ecología ${ }^{12}$. El ordenador es un objeto de consumo, y el acceso a la red exige un desembolso económico. Tales obviedades deben poner de manifiesto que la sociedad del siglo XXI se caracteriza por su alto grado de tecnología, pero ello tampoco está evitando una herencia del siglo anterior: la desigualdad y la pobreza. Del mismo modo, la solución a los problemas educativos no son las TIC.

En resumen, cabe hacer algunas consideraciones generales y particulares sobre el proyecto iniciado en el año 2003.

\footnotetext{
${ }^{12}$ S egún al gunos estudios que cita M ontero (EI País, 23/XI/2004), en tres años quedarán obsoletos 500 millones de ordenadores personales. Eso supone un importante problema de reciclaje, al que hay que añadir que los costos energéticos y ambientales de faricacióndearlquierpC son muy altos. Un monitor consume $240 \mathrm{~kg}$. de combustible fósil, $22 \mathrm{~kg}$. de productos químicos y $1.500 \mathrm{~kg}$. de agua.
} 
En primer lugar, hay que valorar de manera positiva la congruencia y la difusión del proyecto, que abarca el ámbito ciudadano y el espacio educativo bajo el paraguas del derecho a participar en la sociedad del conocimiento con la ayuda de las instituciones públicas.

La apuesta por un determinado tipo de software debe ser valorada también globalmente, pues supone un determinado paso en la geopolítica del control de los medios. A este respecto señalamos el acuerdo alcanzado entre varios países orientales (China, J apón, etc.) para desarrollar una versión de Linux para su mercado, y la reciente compra de la sección de ordenadores de la conocida marca IBM por una empresa china. Dentro de la lógica de la búsqueda de la independencia y del dominio de un solo sistema en el mercado, parece positiva la acción de varias comunidades españolas que se unen a una corriente en la que se prevé la presencia del sistema Linux en la cuarta parte de los ordenadores del mercado mundial en pocos años.

En cuanto a la inversión prevista y al modelo original, bien pueden reorganizarse los presupuestos para dar cabida a las demandas del profesorado y a los resultados del sistema educativo.

A finales de 2004 aparecieron los datos del Informe Pisa 2003 que supusieron una llamada de atención sobre la situación de la secundaria. Para España se tuvieron en cuenta los resultados alcanzados por los países del entorno, con el agravante del pequeño o nulo avance experimentado en los últimos años. A ello puede sumarse la dificultad de mantener un ritmo de implantación de miles de ordenadores en los centros, con el consiguiente problema de gestión y de formación. Quizás los centros no demanden tantos ordenadores y sí otro tipo de recursos materiales y humanos. Las estrategias desarrolladas en otros países (por ejemplo el caso de Finlandia, que ostenta uno de los mejores puestos en resultados educativos) debieran merecer especial atención por los responsables de las políticas de formación del profesorado.

Tal vez la administración no necesite publicitar la ratio alumno/ ordenador que espera al canzar en un futuro cercano, y sí arbitrar medidas de mayor coherencia con las necesidades más prácticas de las escuelas. 
Las virtudes potencialmente educativas de este tipo de medios no están del todo claras para una gran mayoría del profesorado ${ }^{13}$. Cuando este grupo manifieste otro tipo de actitud, podrán darse mejores circunstancias para el uso a gran escala de las TIC en la escuela.

Mientras tanto, es razonable apoyar a los centros y a los profesores que apuestan por introducir en mayor o menor grado el uso de las TIC, y, en paralelo, ofrecer sobre todo formación en aplicación didáctica al grueso del profesorado, que debe ir transformando su rol docente de forma congruente con el cambio cultural y técnico que nos traen los albores del siglo XXI.

\section{BIBLIOGRAFÍA} 22, pp. 27-31.

BARQUIN RUIZ, J. (2004): «Tecnología y diversidad», en Aula de Infantil, núm.

CASTELLS, M. (1998): «La era de la información», en Economía, sociedad y cultura. vol. 3, Fin de milenio, Alianza. Madrid.

DePaRTMENT OF E DUCATION. U.S. (2000): The first year Implementation of The Technology Literacy Challenge Fund in Five States. Characteristics of Case Study States. enero.

EURYDICE (2004): Key Data on Information and Communication Technology in Schools in Europe, Comisión Europea. 18. 338 .

FERIA, A. (2004): «Informática más libre», en Cuadernos de Pedagogía, pp. 14 -

GARGallo Lopez, B. (dir.); Un primer diagnóstico del uso de Internet en los centros escolares de la Comunidad Valenciana. Procesos de formación y efectos sobe la calidad de la educación. Informe mimeo resumido.

Pérez Gómez, A.; Barquín Ruiz, J .; SOto, E. Y SOlA, M. (2004): «Los docentes e Internet: expectativas, desconocimiento y perplejidad», en A. B autista Vera: Las Nuevas Tecnologías en la Enseñanza. Temas para el usuario., cap. 11, pp. 255-267, Akal-UNIA, Madrid.

${ }^{13}$ En un estudio del Departamento de Educación de EE.UU. sobre el uso de distintos fondos dedicados a potenciar las Ticen los centros, se observó cómo en al gunos casos, incluso con ordenadores obsoletos, eran los profesores quienes obtenían un uso notable de los mismos. De igual modo, se advirtió que algunos ordenadores de última generación y con conexión a la red, apenas se utilizaban. Los investigadores opinaron que la tecnología, por sí misma, no es suficiente (Dpt. of Education, enero 2000). 
QUÉAU, P. (2002): «La Sociedad de la Información y el bien público mundial», en J., Vidal Beneyto: La ventana global, pp. 195-208, Taurus, Madrid.

Rodríguez, G. y KNUTH, R. (2000): Critical Issue: Providing Professional Development for Effective Technology Use, North Central Regional Educational Laboratory (http://www.ncrel.org). 